\title{
可见光诱导的铁催化二噁唑酮分子的乃春转移反应
}

\author{
陈佳佳＼cjkstart夏远志*
}

(温州大学化学与材料工程学院 浙江温州 325035)

\section{Visible-Light-Induced Iron Catalysis for Nitrene Transfer Reactions with Dioxazolones}

\author{
Chen, Jiajia Xia, Yuanzhi*
}

(College of Chemistry and Materials Engineering, Wenzhou University, Wenzhou, Zhejiang 325035)

过渡金属催化的乃春转移反应是构建 $\mathrm{C}-\mathrm{N}$ 键的重 要手段之一 ${ }^{[1]}$. 传统方法中, 一般使用有机叠氮、亚胺碘 苯、 $N$-卤代酰胺等作为乃春前体, 但是, 这些方法大多 存在反应条件苛刻、官能团兼容性较差等问题 ${ }^{[2]}$.二噁 唑酮衍生物是近几年被广泛利用的一种新型乃春前体
(Scheme 1) ${ }^{[3-4]}$, 该类化合物具有合成方便、操作简单、 易于存储、反应活性高等特点.

目前，以二噁唑酮衍生物为乃春前体的反应主要集 中在 $\mathrm{C}-\mathrm{H}$ 键的酰胺化 ${ }^{[3-6]}$ 以及硫亚胺 ${ }^{[7-8]}$ 的合成. 在 $\mathrm{Ir}$ 或者 $\mathrm{Ru}$ 催化下，二噁唑酮发生分子内的 $\mathrm{C}\left(\mathrm{sp}^{2}\right)-\mathrm{H}$ 或 (a)<smiles>[R]C1CCC(=O)Nc2ccccc2C1[R]</smiles>

(d)

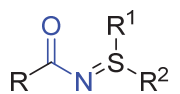

(e)<smiles>[R1][Sb](CC)=[SH]C(=O)CCCC</smiles>

(f)

(g)

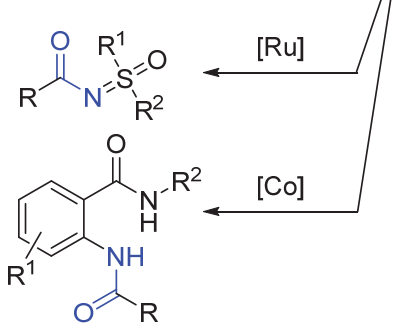

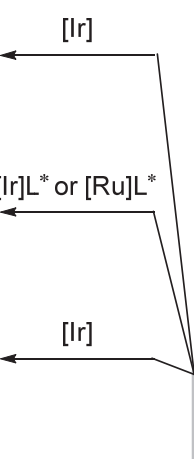

$[\mathrm{Ru}]$

$[R u] L^{*}$<smiles>C1CCC1</smiles>

carboxylic acids or carboxylic acid derivatives

图式 1 二噁唑酮作为乃春前体参与的反应

Scheme 1 Reactions using dioxazolones as nitrene precursors

* Corresponding author. E-mail: xyz@wzu.edu.cn. Published online August 25, 2021. 
$\mathrm{C}\left(\mathrm{sp}^{3}\right)-\mathrm{H}$ 酰胺化反应可高效合成系列二氢喹啉酮或 $\gamma-$ 内酰胺衍生物 (Schemes $1 \mathrm{a} \sim 1 \mathrm{c}$ ). 在导向基的协助下, 通过 Rh、Ir、Co 等金属的催化, 可实现以二噁唑酮衍生 物为胺源的分子间芳基和烷基的 $\mathrm{C}-\mathrm{H}$ 酰胺化反应 (Schemes $1 \mathrm{~g} \sim 1 \mathrm{i}, 1 \mathrm{k} \sim 1 \mathrm{~m}$ ). 值得注意的是, 烯丙位的 $\mathrm{C}\left(\mathrm{sp}^{3}\right)-\mathrm{H}$ 键酰胺化反应可在无导向基作用下发生. 在 $\mathrm{Ru}$ 催化下, 二噁唑酮衍生物与硫醚或者亚砜反应, 可得 到相应的硫亚胺或硫酰亚胺化合物, 并且在手性配体的 调控下可实现硫手性中心的构建(Schemes $1 \mathrm{~d} \sim 1 \mathrm{f}$ ).

前期研究主要以贵金属催化的反应为主, 廉价金属 催化的二噁唑酮乃春转移反应相对少见 ${ }^{[3-6]}$. 过渡金属 铁在地壳元素含量中排名第四, 不仅价格低廉, 而且环 境友好、几乎无毒, 铁催化剂的应用受到了广泛关注 ${ }^{[9]}$. 最近, 大连理工大学精细化工国家重点实验室包明课题 组 ${ }^{[10]}$ 报道了可见光诱导的铁催化二噁唑酮分子的乃春 转移反应(Scheme 2), 实现了温和条件下 $\mathrm{C}\left(\mathrm{sp}^{3}\right)-\mathrm{N}$, $\mathrm{N}=\mathrm{S}$ 和 $\mathrm{N}=\mathrm{P}$ 键的高效构建.

作者首先以 3-苯基-1,4,2-二噁唑-5-酮与 1,3-二苯 基-1,3-丙二酮的 $\mathrm{C}-\mathrm{H}$ 酰胺化反应为模板, 对催化剂、 溶剂以及光源波长等条件进行了笁选, 得出最优反应条 件为: $\mathrm{FeCl}_{3}$ (15 mol\%)为催化剂, 二氯甲烷(DCM)为溶 剂, $450 \mathrm{~nm}$ 蓝光照射, $40{ }^{\circ} \mathrm{C}$ 下反应 $16 \mathrm{~h}$. 在此条件下, 作者对反应的普适性进行了研究, 分别对二噁唑酮与 1,3-二羰基化合物的底物范围进行了拓展, 实验表明含 不同电子和位阻效应取代基的底物均可兼容. 当该条件 应用于反应活性较弱的二苯基甲烷时, 仅得到 $26 \%$ 的产
物. 研究发现, 加入 $15 \mathrm{~mol} \% \mathrm{AgNTf}_{2}$ 添加剂可显著提升 反应效率，实现了系列二芳基甲烷衍生物的 C-H 胺化反 应.

随后，作者以硫醚、亚砜和有机膦化合物作为捕获 试剂, 成功将该乃春转移反应应用于 $\mathrm{N}=\mathrm{S}$ 和 $\mathrm{N}=\mathrm{P}$ 键的 构建. 对于亚砜类化合物, $\mathrm{FeCl}_{3}$ 的用量可降至 $10 \mathrm{~mol} \%$; 当使用硫醚作为捕获试剂时, $\mathrm{FeBr}_{3}$ 催化剂的活性更高, 其用量可降低至 $5 \mathrm{~mol} \%$, 反应几乎可以定量进行; 对于 有机膦类化合物, 以 $5 \mathrm{~mol} \%$ 的 $\mathrm{FeCl}_{3}$ 为催化剂, 反应时 间缩短至 $15 \mathrm{~min}$ 即可定量得到膦亚胺产物. 这些乃春捕 获反应具有优良的官能团兼容性和底物普适性，产物分 离收率可达 99\%.

为了揭示反应机理, 作者进行了控制实验和密度泛 函理论(DFT)计算研究. 动力学同位素效应研究显示氢 原子转移不是反应的决速步; 使用苯甲酰胺作为底物时 无 $\mathrm{C}-\mathrm{H}$ 胺化反应发生，表明其不是该反应的中间体. 当反应中分别加入 2,6 -二叔丁基-4-甲基苯酚(BHT)和四 甲基哌啶氧化物(TEMPO)时，可捕获到相应的中间体， 表明该乃春转移反应可能是自由基反应. DFT 计算表明, 可见光调控铁-二噁唑酮物种自旋态由六线态到四线态 的转变促进了二噁唑酮分子脱除二氧化碳; 并且, 在四 线态势能面上进行的分子间氢原子转移(HAT)反应很容 易发生; 后续的分子间的自由基重组更容易在六线态的 势能面进行. 根据理论和实验研究结果, 作者提出的催 化循环过程如 Scheme 3 所示. 基态的六线态铁催化剂 与二啞唑酮的氮原子配位生成六线态的铁配合物

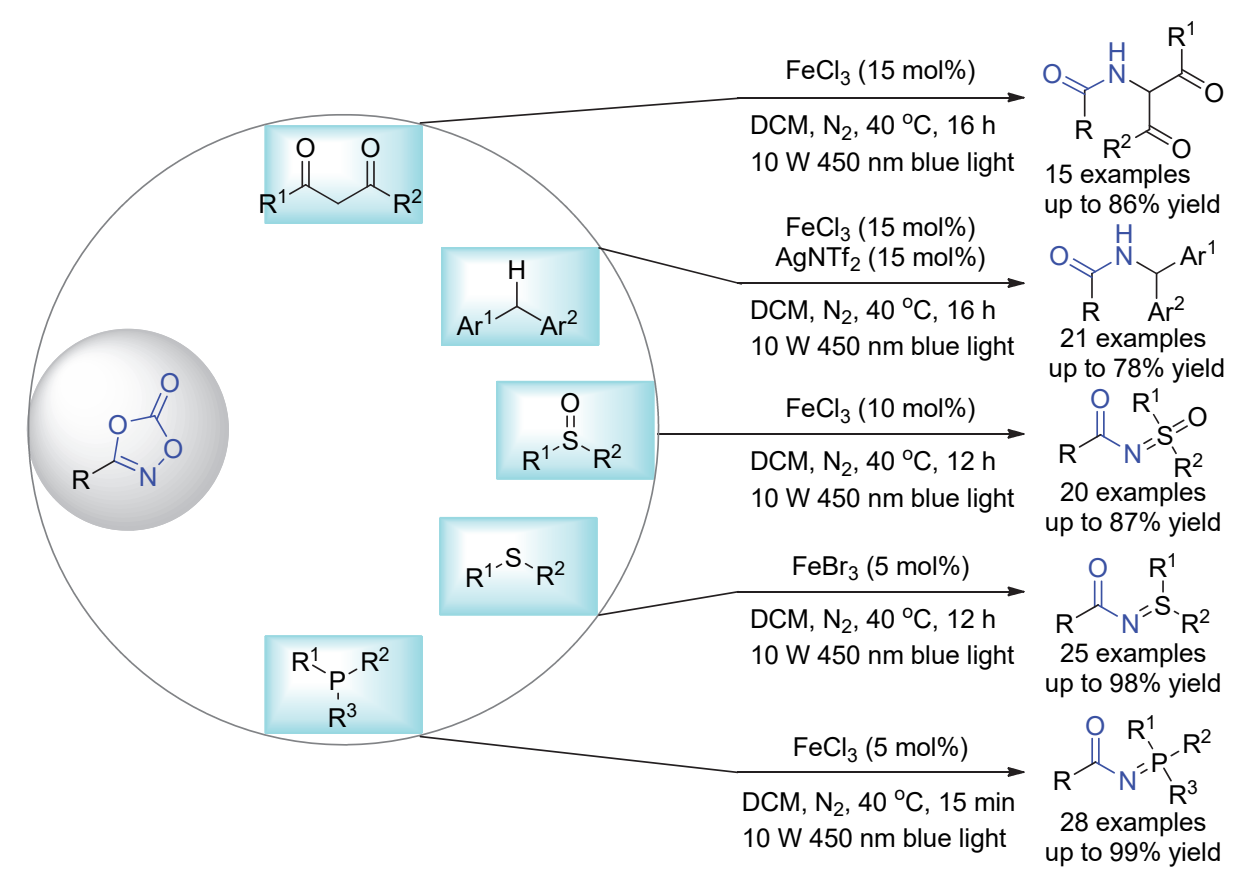

图式 2 可见光诱导的铁催化二啞唑酮分子的乃春转移反应

Scheme 2 Visible-light-induced iron catalysis for nitrene transfer reactions with dioxazolones 


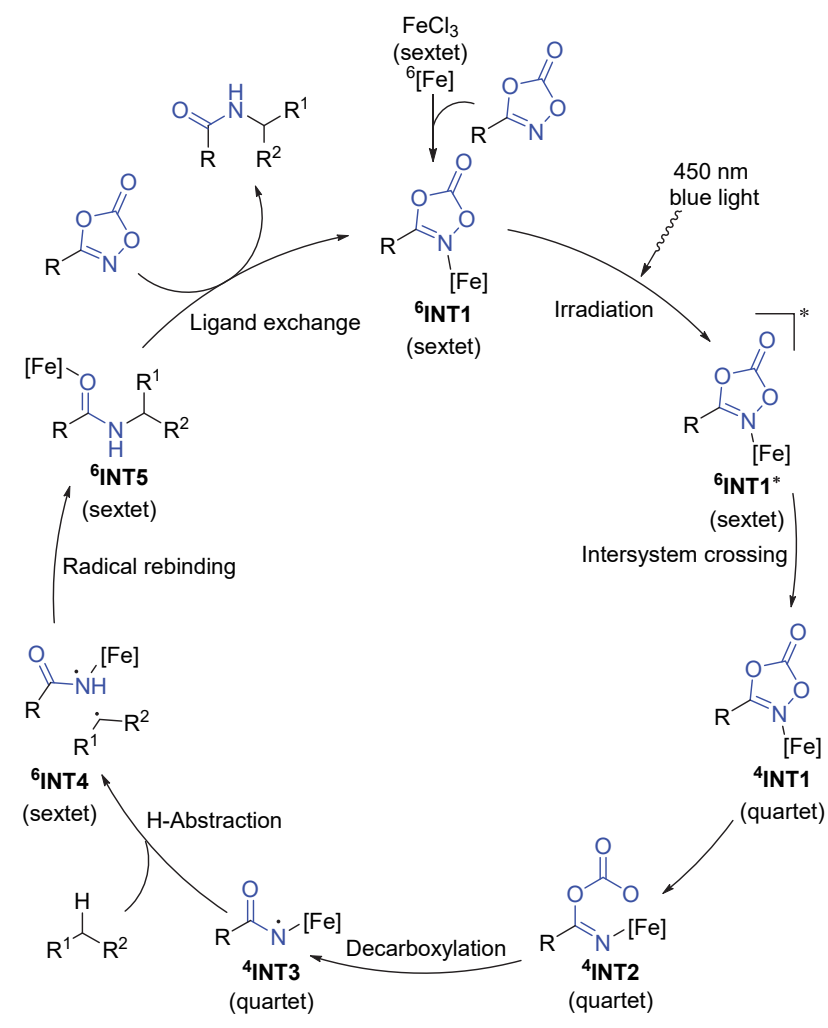

图式 3 提出的反应机理

Scheme 3 Proposed reaction mechanism

${ }^{6}$ INT1，配合物 ${ }^{6} \mathrm{INT} 1$ 被可见蓝光激发并通过自旋反 转生成四线态铁配合物 ${ }^{4}$ INT1. 通过分子内 $\mathrm{N}-\mathrm{O}$ 键断 裂得到 ${ }^{4} \mathbf{I N T}$, 再经过 $\mathrm{C}-\mathrm{O}$ 键断裂并脱除二氧化碳得
到四线态的铁乃春中间体 ${ }^{4}$ INT3. 最后，经过分子间的 氢原子转移、自由基重组、配体交换等步骤即可得到酰 胺化产物.

综上所述，包明课题组 ${ }^{[10]}$ 发展了基于可见光诱导 的铁催化二噁唑酮分子的乃春转移反应，实现了构建 $\mathrm{C}\left(\mathrm{sp}^{3}\right)-\mathrm{N} 、 \mathrm{~N}=\mathrm{S}$ 和 $\mathrm{N}=\mathrm{P}$ 键的新方法. 该反应使用廉 价的铁盐作为催化剂, 无需额外的光敏剂和配体, 具有 条件温和、底物范围广、官能团兼容性好等优点. 结合 实验和理论计算研究，作者提出了基于铁-二啞唑酮物 种自旋态转变的自由基反应机理, 很好地解释了实验结 果.

\section{References}

[1] Dequirez, G.; Pons, V.; Dauban, P. Angew. Chem., Int. Ed. 2012, 51, 7384.

[2] Shin, K.; Kim, H.; Chang, S. Acc. Chem. Res. 2015, $48,1040$.

[3] van Vliet, K. M.; de Bruin, B. ACS Catal. 2020, 10, 4751.

[4] Shimbayashi, T.; Sasakura, K.; Eguchi, A.; Okamoto, K.; Ohe, K. Chem. Eur. J. 2019, 25, 3156.

[5] Trowbridge, A.; Walton, S. M.; Gaunt, M. J. Chem. Rev. 2020, 120, 2613.

[6] Hayashi, H.; Uchida, T. Eur. J. Org. Chem. 2020, 909.

[7] Bizet, V.; Hendriks, C. M. M.; Bolm, C. Chem. Soc. Rev. 2015, 44, 3378.

[8] Zhang, X.; Lin, B.; Chen, J.; Chen, J.; Luo, Y.; Xia, Y. Org. Lett. 2021, 23, 819 .

[9] Bauer, I.; Knolker, H. J. Chem. Rev. 2015, 115, 3170.

[10] Tang, J.-J.; Yu, X.; Wang, Y.; Yamamoto, Y.; Bao, M. Angew. Chem., Int. Ed. 2021, 60, 16426. 